\title{
Spatial location judgments: A cross-national comparison of estimation bias in subjective North American geography
}

\author{
ALINDA FRIEDMAN \\ University of Alberta, Edmonton, Alberta, Canada \\ DENNIS D. KERKMAN \\ Southwest Texas State University, San Marcos, Texas \\ and \\ NORMAN R. BROWN \\ University of Alberta, Edmonton, Alberta, Canada
}

\begin{abstract}
We examined alternate explanations for distortions in the subjective representation of North American geography. One explanation, based on physical proximity, predicts that bias in location estimates should increase with the distance from a participant's home city or region. An alternative is that biases arise from combining accurate and inaccurate beliefs about the cities and the superordinate regions to which they belong, including beliefs that may have social or cultural origins. To distinguish these, Canadians from Alberta and Americans from Texas judged the latitudes of cities in Canada, the U.S., and Mexico. The Texans' estimates of Mexican locations were $16^{\circ}$ (approximately 1,120 miles) more biased than their estimates of Canadian locations that were actually about 840 miles farther away. This finding eliminates proximity as a primary source of geographic biases and underscores the role of categorical beliefs as an important source of biased judgments.
\end{abstract}

In this article, we examine alternate explanations for biases in geographical beliefs. Though we focus on the tendency among North Americans to estimate some locations to be farther south than they actually are, the principles underlying this bias should generalize to other geographic distortions and to reasoning processes within other realworld domains. For example, geographicalentities typically have well-known hierarchical relations (e.g., neighborhoods within cities; cities within regions; regions within continents), yet knowledge about specific geographic locations is often uncertain or absent altogether. Examining how people reason about geography may thus shed light on how categorical knowledge and uncertainty affect judgment and decision-making more generally (see, e.g., Huttenlocher, Hedges, \& Duncan, 1991; Huttenlocher, Hedges, \& Vevea, 2000; McNamara \& Diwadkar, 1997; Newcombe, Huttenlocher, Sandberg, Lie, \& Johnson, 1999).

In our initial investigations of subjective geography (Friedman \& Brown, 2000a, 2000b), Canadian participants divided North America into four major regionsCanada, the northern United States, the southern United

This research was supported by grants from the Natural Sciences and Engineering Council of Canada and the U.S. National Science Foundation. We are grateful to Lorna Price for writing the experimental program, and to her, Alanna McCormick, and Reyna Wilson for help in collecting and analyzing the data. Correspondence should be addressed to A. Friedman, Department of Psychology, University of Alberta, Edmonton, AB, T6G 2E9 Canada (e-mail: alinda@ualberta.ca).
States, and Mexico-with little discrimination among the locations of cities within these regions. Their latitude estimates were roughly accurate for Canadian cities, but the estimates became increasingly biased as the cities were located increasingly farther south. Indeed, Mexican cities whose mean latitude was $21^{\circ} \mathrm{N}\left(S E=1.2^{\circ}\right)$ were judged to be located at the equator (Friedman \& Brown, 2000b, Experiment 2); an error approximately equivalent to the distance from Boston to Miami.

This pattern of data is consistent with the notion that estimation bias should increase with increasing physical distance from one's own region. There is other evidence for such a proximity hypothesis (Golledge, 1993; Tobler, 1970). For example, Lundberg and Ekman (1973) found that the estimated distance between cities was a power function of the geographic circle distance between them, and that bias increased with increasing distance from the home city of the participants.

Physical proximity might influence judgments for a variety of reasons. For example, similarity to other locations generally decreases (Golledge, 1993; Tobler, 1970) and uncertainty about them increases (Tobler, 1961) with increasing distance from one's home. Along similar lines, in recent models of estimation processes (Huttenlocher et al., 1991; Huttenlocher et al., 2000; Newcombe et al., 1999), bias is predicted to increase with uncertainty, and in spatial domains it is predicted to increase with increasing distance from a landmark (see McNamara \& Diwadkar, 1997). If we assume 
that a person's home city functions like a landmark and that uncertainty (inexactness in the representation) increases with increasing distance from this landmark (e.g., Tobler, 1961), then these assumptions also predict that bias in location judgments should increase with increasing distance from a participant's home region. Thus, it is reasonable that Canadians' location estimates became more biased as the estimated locations became more southerly. Presumably, people from Mexico or the southern U.S. would be less biased in their estimates of cities in those regions and more biased in their estimates of locations in Canada.

The main purpose of the present study was to examine whether physical proximity is the primary factor underlying biases in subjective geography. The most direct way to do this entails testing participants from different locations. Accordingly, in the present study, Canadians from Edmonton, Alberta, and Americans from San Marcos, Texas, estimated the latitudes of 10 cities in each of the four major regions that formed the subjective geography of the North American continent for the Canadian participants in our earlier studies (Friedman \& Brown, 2000a, 2000b). The Albertans lived approximately $2,560 \mathrm{~km}$ (1,600 miles) north of the Mexican border, whereas the Texans lived approximately $320 \mathrm{~km}$ (200 miles) north of it. Thus, the proximity hypothesis predicts that the Albertans should have the largest bias in their Mexican estimates, whereas the Texans should have relatively accurate estimates of Mexican locations and have the largest bias in their Canadian estimates.

Alternate explanations for the genesis of geographical biases derive from the notion that people use plausible reasoning processes to make both absolute and relative location judgments (Friedman \& Brown, 2000a, 2000b; Friedman, Brown, \& McGaffey, 2002; see also Collins \& Michalski, 1989; Stevens \& Coupe, 1978). An important tenet of this theory is that in complex knowledge domains, people use many kinds and sources of information to inform their judgments. From this approach, proximity is merely one of several factors that may affect judgments about geography. Some others include (1) the participants' conceptual representation(s) of the domain (e.g., the locations of regions relative to global reference points and the hierarchical and adjacent relations among them); (2) the dimension(s) of knowledge believed relevant to location judgments (e.g., climate); and (3) the set of cities being judged, together with beliefs about the similarity among them or their superordinate regions.

Our earlier work (Friedman \& Brown, 2000a, 2000b) provided evidence that beliefs about the locations of even relatively familiar cities reflect beliefs about the locations of the cities' superordinate regions relative to global landmarks (e.g., the equator), which in turn may be influenced by beliefs about climate, terrain, type of agriculture, and so on. For example, Canadians underestimated the location of Mediterranean cities relative to their actual locations by about the same amount as they underestimated the location of cities in the southern U.S. relative to their actual locations. Subsequent research showed that these distant regions were functionally linked (Friedman \& Brown, 2000b), and we attributed the association to beliefs about similarities in climate.
Though beliefs about climate are arguably relevant to a north-south location estimate, location judgments might also be influenced by factors that are less relevant, such as beliefs about cultural similarities and differences between peoples and places (Hofstede, 1980; Kerkman, Stea, Norris, \& Rice, 2002; Pinheiro, 1998; Saarinen, 1973, 2000; Saarinen \& MacCabe, 1995). Similarly, people tend to exaggerate the distance between points across geopolitical borders (see, e.g., Maki, 1981). We do not intend to distinguish among the various cognitive, cultural, and national sources of estimation bias here, or to delineate the mechanisms by which they operate; we intend only to test them in aggregate against the proximity hypothesis.

In addition to determining whether proximity is an important source of geographic biases, we had two additional goals for the present study. The second goal was to determine the subjective North American geography of the Texan participants. Canadians may divide the United States into two main regions, but there is no a priori reason for Americans to do exactly the same. For example, Americans might have additional geographic categories (e.g., the northeast, the midwest). Furthermore, even if both groups place North American cities into the same four regions, there is an important theoretical distinction between which geographic categories exist and where people believe the regions that they represent are located. For example, Texans might not underestimate the location of the southern U.S. region as much as Albertans; indeed, on the proximity hypothesis, Texans should not have biased estimates for this region.

The third goal of the present study concerned our interest in how geographic biases might be corrected. In our previous work, informing participants about the actual location of a relatively small number of judiciously selected "seed" cities (e.g., cities near regional borders) eliminated the biases in their judgments (Friedman \& Brown, 2000b; see also Brown \& Siegler, 1993, 1996, 2001). The malleability of distortions in the knowledge base to accommodate new information constitutes important evidence for the plausible reasoning approach (Friedman \& Brown, $2000 \mathrm{~b}$ ) and is not easily predicted by the proximity hypothesis. In the present study, therefore, we obtained estimates both before and after giving participants accurate information about locations near the Canadian-U.S. and U.S.-Mexican borders. Not only should this replicate our previous findings, it should demonstrate that seeding would be equally effective in correcting biases across groups whose initial biases might be quite different.

\section{METHOD}

\section{Participants, Stimuli, and Design}

University students who were born in Canada and were attending the University of Alberta and university students who were born in the U.S. and were attending Southwest Texas State University participated in partial fulfillment of course requirements at each institution. Well over $90 \%$ of the undergraduate population at each institution had been resident for at least 1 year in their province or state.

Because the latitudes of the seed cities were displayed on the screen throughout the second estimates, we eliminated from consideration the data of participants who did not correctly estimate the location 
of more than one of the four seed cities during these trials. Four participants were eliminated from the Albertan data and 5 from the Texan data, which left 46 participants from each country whose data were used in the analyses.

All participants estimated the locations of 44 cities: 10 in each of the four regions, plus 4 seed cities. The 40 experimental cities used are shown on the abscissa of Figure 1 . They were presented in a different random order for each participant and for each set of estimates.

The seed cities were selected to illustrate the overlap between Canada and the northern U.S. (Ottawa and Minneapolis, each at $45^{\circ}$ ) and between the southern U.S. and Mexico (Dallas and Tijuana, each at $\left.33^{\circ}\right)$. Data from the seed cities were not included in any of the analyses.

\section{Procedure}

When participants arrived, they were seated at a computer terminal. They first rated their knowledge of each of the cities on a scale from 0 (no knowledge) to 9 (a lot of knowledge), using the numeric keypad on the keyboard to provide their responses. The instructions emphasized knowledge in general, not just knowledge about locations.

We next described the metric for latitudes - that the equator is at $0^{\circ}$, the North Pole is at $90^{\circ} \mathrm{N}$ and the South Pole is at $90^{\circ} \mathrm{S}$ - and asked the participants to provide us with latitude estimates of all the cities. They again used the keypad to enter their numeric responses, followed by either an "N" or an " $\mathrm{S}$ " to indicate whether the city was in the northern or southern hemisphere.

The first estimates were followed by the introduction of the seed facts. The participants were told that the information was the actual latitudes of the four cities shown and were asked to make a second set of estimates. The seeds remained on the screen throughout the second estimates.

\section{Data Analysis}

We conducted both participant and item analyses of variance (ANOVAs) on the first and second estimates, the signed and absolute errors for each set of estimates, and the knowledge ratings. A $p<.05$ criterion for significance was used. For the participant ANOVAs, the measures for each participant were averaged over the 10 cities in each region; group (Texan or Albertan) was between participants and region (Canada, northern U.S., southern U.S., and Mexico) was within participants. For item analyses, each measure was averaged over participants for each city; group was within items and region was between items.

For these designs, the interaction terms are identical in the analyses of signed errors and absolute latitude estimates because signed error is computed by subtracting the actual from the estimated latitude for each city and participant and averaging over either items or participants. However, the estimates expressed as signed errors reveal the direction of a bias if it exists: Positive numbers indicate a northward bias and negative numbers indicate a southward bias.

Absolute errors were computed by averaging the absolute values of the signed errors. This is a measure of overall accuracy, whether or not the data are biased. For example, if half the participants show $\mathrm{a}+30^{\circ}$ (northerly) bias for a given city and the remainder show a $-30^{\circ}$ (southerly) bias, the bias (signed error) would be $0^{\circ}$ but the absolute error would be $30^{\circ}$. Thus, participants can, in principle, be inaccurate but unbiased. The proximity hypothesis holds that both signed and absolute error should increase with increasing distance from the home city.

\section{RESULTS}

\section{Initial Estimates}

Three findings are apparent in Figure 1, which shows the item means for the first set of estimates. First, both groups divided the North American continent (through to Mexico) into the same four regions, comprising the same cities. Sec- ond, whereas Albertans were relatively accurate in their location estimates of the two northern regions, the Texans overestimated the locations of these regions. Third, and most important, both groups underestimated the locations of the two southernmost regions. Furthermore, despite their large differences in distance to Mexico, both the Texans and the Albertans projected the location of cities in Mexico far to the south of their actual locations. Indeed, the Texans projected Mexico to be farther south than the Albertans did by about $10^{\circ}$, or $1,120 \mathrm{~km}$ (700 miles) and also had a larger absolute error ( $35^{\circ}$ vs. $24^{\circ}$, respectively).

In accord with these observations, the analyses of the signed errors- which is a direct measure of the amount of bias in the estimates-yielded a reliable group (Texan, Albertan) by region (Canada, northern U.S., southern U.S., Mexico) interaction $\left[F_{1}(3,270)=14, M S_{\mathrm{e}}=224\right.$, and $\left.F_{2}(3,36)=129, M S_{\mathrm{e}}=5\right]$. The mean signed errors for cities in Canada, the northern U.S., the southern U.S., and Mexico were $2^{\circ},-4^{\circ},-10^{\circ}$, and $-22^{\circ}$ for the Albertans, and $16^{\circ}$, $7^{\circ},-14^{\circ}$, and $-32^{\circ}$ for the Texans, respectively. Similarly, the ANOVAs on the absolute errors yielded a reliable interaction for items $\left[F_{2}(3,36)=14, M S_{\mathrm{e}}=3\right]$, though not for participants. The mean absolute error for cities in Canada, the northern U.S., the southern U.S., and Mexico was $8^{\circ}$, $9^{\circ}, 12^{\circ}$, and $23^{\circ}$ for the Albertans, and $23^{\circ}, 18^{\circ}, 21^{\circ}$, and $35^{\circ}$ for the Texans, respectively. Figure 2 shows the signed and absolute errors for both groups. It is evident from the figure that both groups showed the largest bias and the least accuracy in their judgments of the Mexican cities.

It is also obvious from Figure 1 that the range of the Texans' estimates was larger than the range for the Albertans. Consequently, to correct for scale differences, we computed the signed and absolute error for each city as a percentage of the range of each participant's latitude estimates, and we used those data in the designs described above. For signed errors, the group $\times$ region interaction remained reliable $\left[F_{1}(3,270)=6, M S_{\mathrm{e}}=117\right.$, and $\left.F_{2}(3,36)=26, M S_{\mathrm{e}}=5\right]$. For absolute errors, the interaction was now reliable for both the participant and item ANOVAs $\left[F_{1}(3,270)=8, M S_{\mathrm{e}}=93\right.$, and $F_{2}(3,36)=42$, $\left.M S_{\mathrm{e}}=4\right]$. The means for both measures are shown in Table 1. Interestingly, when the range of responses was controlled there was no difference between Texans and Albertans in their absolute error for the Mexican cities ( $28 \%$ vs. $31 \%$ of the range, respectively) or for cities in the southern U.S. (16\% vs. $18 \%$ of the range).

In sum, whether we considered signed error, absolute error, or the percentage of the overall range in estimates for each region on each of these measures, both groups of participants displayed the least accuracy and the largest bias in their estimates of Mexican cities. Neuman-Keuls tests conducted separately for each group on all four measures confirmed this observation. ${ }^{1}$

The data for the Texans are particularly important in disproving the proximity hypothesis. Even though the Mexican cities were on average about $12^{\circ}(840$ miles $)$ closer to the Texans' home city than to the Canadian cities, the magnitude of the error in the Texans' location estimates was larger for the Mexican cities than for the Canadian 


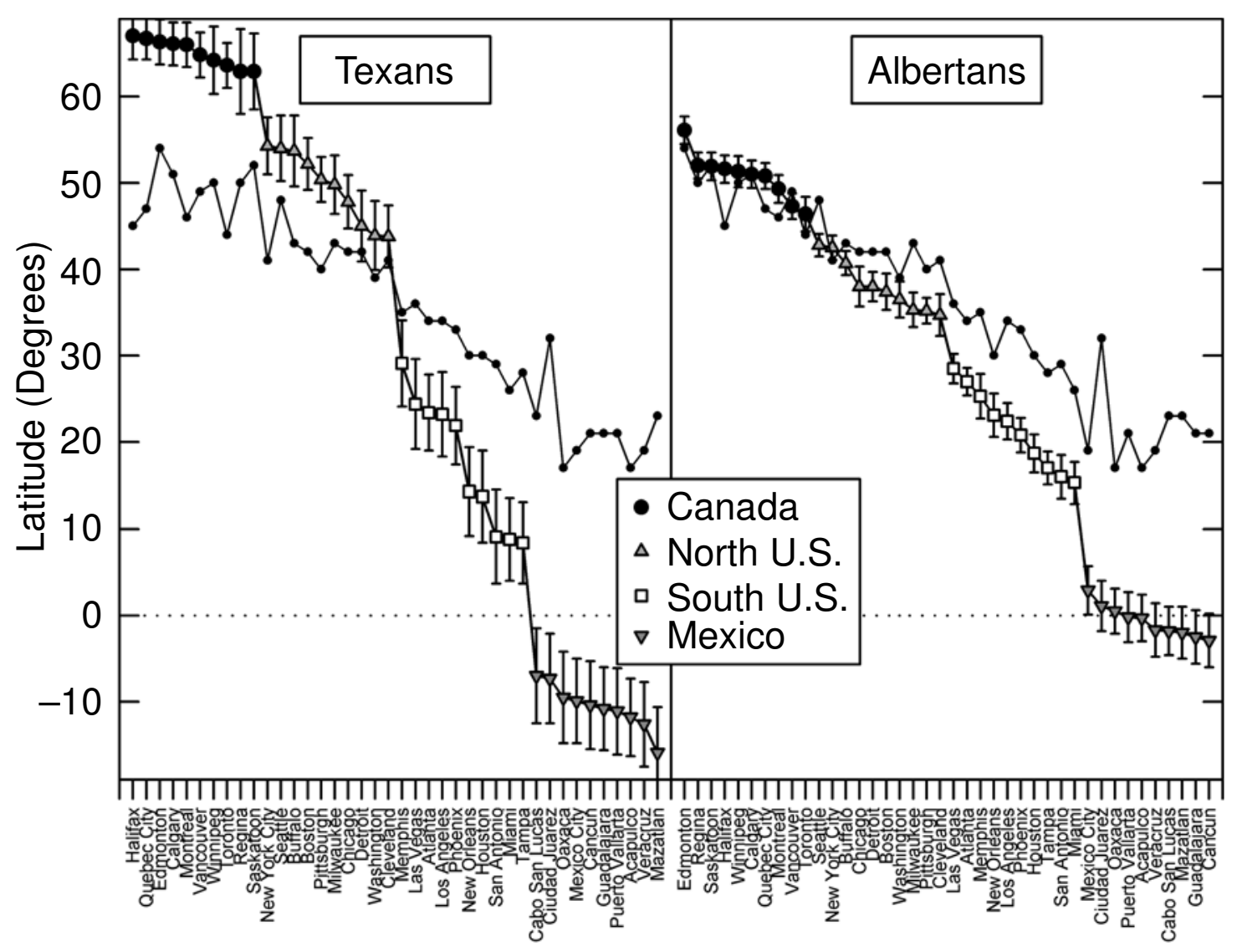

Figure 1. The actual latitudes (small circles) are plotted together with the average first latitude estimates, obtained by averaging across participants for each of the $\mathbf{4 0}$ test cities. These subjective location profiles are ordered according to the magnitude of the first estimates, separately for the Texan and Albertan participants, from the northernmost city at the left of each panel to the southernmost city at the right. Error bars are standard errors of the mean for each city, computed over participants.

cities in both an absolute sense and when differences between participants in the range of their estimates was controlled. A similar pattern of findings was seen in the Albertans' estimates, though of course, for these participants, the Mexican cities actually were the farthest from their home city. Thus, the location estimate data converge on the view that the overall proximity of the participants to the locations being estimated could not have been the primary factor underlying the bias observed in the estimates.

Although participants never compared any cities directly, we could construct a measure of subjective "distance from home" by subtracting the estimate made by each participant for a given city from the estimate for that participant's home city: either Edmonton or San Antonio.2 The means for each region are shown in Table 2. On this measure, the Texans appear to have placed Canada farther from them than Mexico. But this (correct) belief about the relative locations of regions does not address the issue of bias in the actual estimates. That is, built in to the "estimated" distance to the Canadian cities is the $14^{\circ}$ error (in the other direction) for the Texans' location estimates for cities in the southern U.S.; the absolute magnitude of the distances computed from these estimates thus includes the underlying category biases but obscures their direction and magnitude. Indeed, we now have direct evidence that the underlying category structure and regional biases observed in Figure 1 are responsible for biases in distance estimates (Brown, Friedman, \& Lee, 2002).

In sum, whereas the subjective distance from home increased with the actual distance, neither accuracy nor bias in the latitude estimates themselves showed such a monotonic increase for the Texans. Because it is unreasonable that physical proximity underlies Albertan but not Texan judgments, the data from the Texans rule out physical proximity to the home city - whether actual or estimatedas the primary cause of estimation bias.

\section{Second Estimates}

The Albertans and Texans both benefited from the information conveyed by the seed facts (see Figure 3 for the item means and Figure 4 for the participant means and a comparison with the first estimates). Whereas the average 


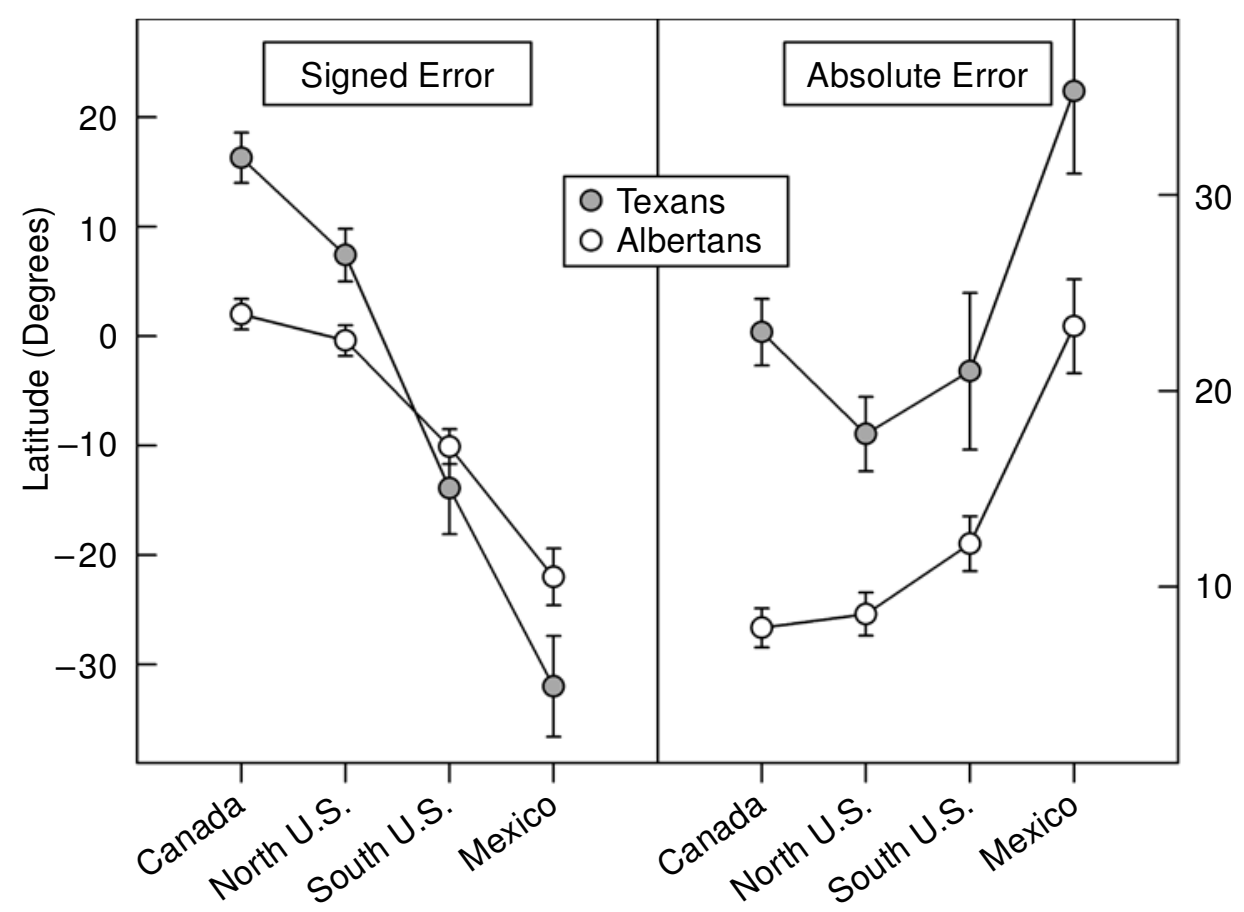

Figure 2. The average signed and absolute errors in the first estimates for both groups of participants for the 10 cities within each of the four subjective North American regions identified in our previous research (Friedman \& Brown, 2000a, 2000b). Signed errors are a measure of the north-south direction of the bias in the estimates; absolute errors are a measure of accuracy irrespective of the direction of the bias. Error bars are standard errors of the means within regions, computed across participants.

absolute error in the first estimates was $13^{\circ}$ and $24^{\circ}$ for the Albertans and Texans, respectively, the average absolute error in the second estimates was $5^{\circ}$ and $6^{\circ}$. Nevertheless, there were still differences between the groups, underscored by the significant interaction between group and region in the analysis of the signed errors for the second estimates $\left[F_{1}(3,270)=4, M S_{\mathrm{e}}=32\right.$, and $F_{2}(3,36)=18$, $\left.M S_{\mathrm{e}}=1\right]$. It can be seen in Figures 3 and 4 that the Albertans overestimated the locations of the two southernmost regions more than the Texans did in their second estimates. Nevertheless, the second estimates were far more accurate than the first estimates for both groups (there was no group $\times$ region interaction for absolute errors), and the ranges were also more similar.

\section{Knowledge Ratings}

Not surprisingly, both groups claimed more knowledge about cities in their own regions than about cities in the other three: The average knowledge ratings for cities in Canada, the northern U.S., the southern U.S., and Mexico were 6.5, 3.4, 3.7, and 1.2 for the Albertans, and 2.2, 5.3, 6.5 , and 2.8 for the Texans, yielding a reliable interaction

Table 1

Signed and Absolute Errors of the First Estimates, Computed as a Percentage of the Range of First Estimates for Each Participant, Averaged Across Cities Within Regions for Each Participant and Then Across Participants

\begin{tabular}{|c|c|c|c|c|c|c|c|c|}
\hline \multirow[b]{3}{*}{ Measure } & \multicolumn{8}{|c|}{ Region } \\
\hline & \multicolumn{2}{|c|}{ Canada } & \multicolumn{2}{|c|}{ Northern U.S. } & \multicolumn{2}{|c|}{ Southern U.S. } & \multicolumn{2}{|c|}{ Mexico } \\
\hline & $M$ & $S E$ & $M$ & $S E$ & $M$ & $S E$ & $M$ & $S E$ \\
\hline \multicolumn{9}{|c|}{$\%$ Signed Error } \\
\hline Texans & 16.9 & 2.1 & 8.7 & 1.9 & -8.1 & 2.8 & -22.4 & 3.2 \\
\hline Albertans & 2.1 & 2.4 & -5.4 & 2.3 & -13.7 & 2.5 & -27.1 & 2.9 \\
\hline \multicolumn{9}{|c|}{ \% Absolute Error } \\
\hline Texans & 21.8 & 1.2 & 16.0 & 1.2 & 16.0 & 2.4 & 28.1 & 2.3 \\
\hline Albertans & 11.9 & 1.7 & 12.7 & 1.7 & 17.7 & 2.1 & 30.6 & 2.1 \\
\hline
\end{tabular}


Table 2

Distance From Home in Degrees, Computed From Both the Actual Latitudes of the Test Cities and From the First Latitude Estimates, Averaged Across Cities Within Regions for Each Participant and Then Across Participants

\begin{tabular}{|c|c|c|c|c|c|c|c|c|}
\hline \multirow[b]{3}{*}{ Measure } & \multicolumn{8}{|c|}{ Region } \\
\hline & \multicolumn{2}{|c|}{ Canada } & \multicolumn{2}{|c|}{ Northern U.S. } & \multicolumn{2}{|c|}{ Southern U.S. } & \multicolumn{2}{|c|}{ Mexico } \\
\hline & $M$ & $S E$ & $M$ & $S E$ & $M$ & $S E$ & $M$ & $S E$ \\
\hline \multicolumn{9}{|c|}{ Actual Distance } \\
\hline Texans & 19.8 & 1.0 & 13.1 & 1.0 & 3.3 & 1.0 & 8.3 & 1.0 \\
\hline Albertans & 5.2 & 1.0 & 11.9 & 1.0 & 22.5 & 1.1 & 32.7 & 1.4 \\
\hline \multicolumn{9}{|l|}{ Est. Distance } \\
\hline Texans & 56.0 & 5.2 & 40.9 & 5.1 & 13.0 & 2.1 & 26.2 & 3.0 \\
\hline Albertans & 6.2 & 0.5 & 18.3 & 1.3 & 34.7 & 1.8 & 56.8 & 3.1 \\
\hline
\end{tabular}

between region and group $\left[F_{1}(3,270)=289, M S_{\mathrm{e}}=1\right.$, and $\left.F_{2}(3,36)=80, M S_{\mathrm{e}}=1\right]$. The difference between groups in their self-assessed knowledge was reliable for each of the regions $[t(90)=14,-5,-9$, and -5 , respectively].

Each group felt that they knew about the same amount (6.5 on the 9-point scale) for cities in their own region, and more about that region than about any of the other three. In addition, both groups claimed that they knew relatively little about the Mexican cities, though the average rating for the Texans was about twice that of the Albertans [2.8 vs. 1.2 , respectively, $t(90)=5.34$ ]

Knowledge ratings should reflect uncertainty about the cities along many dimensions, not just that of location. Although it is tempting to try to explain biases in terms of knowledge or familiarity, the pattern of bias did not consistently follow the pattern of the knowledge ratings, either within or between groups.

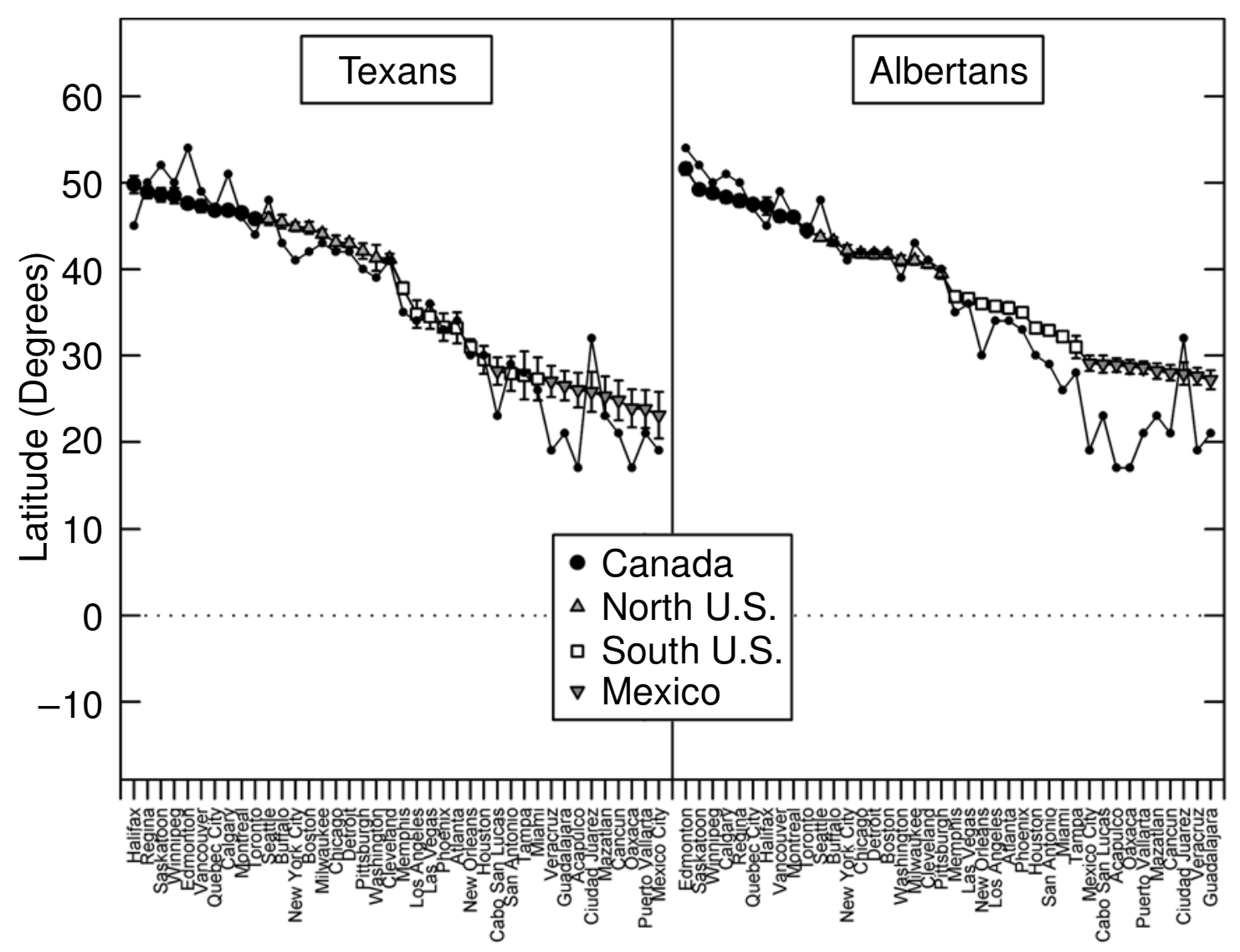

Figure 3. The actual latitudes (small circles) are plotted together with the average second latitude estimates, obtained by averaging across participants for each of the $\mathbf{4 0}$ test cities. The data are ordered from the northernmost estimate at the left of each panel to the southernmost at the right. Error bars are standard errors of the mean for each city, computed over participants. 


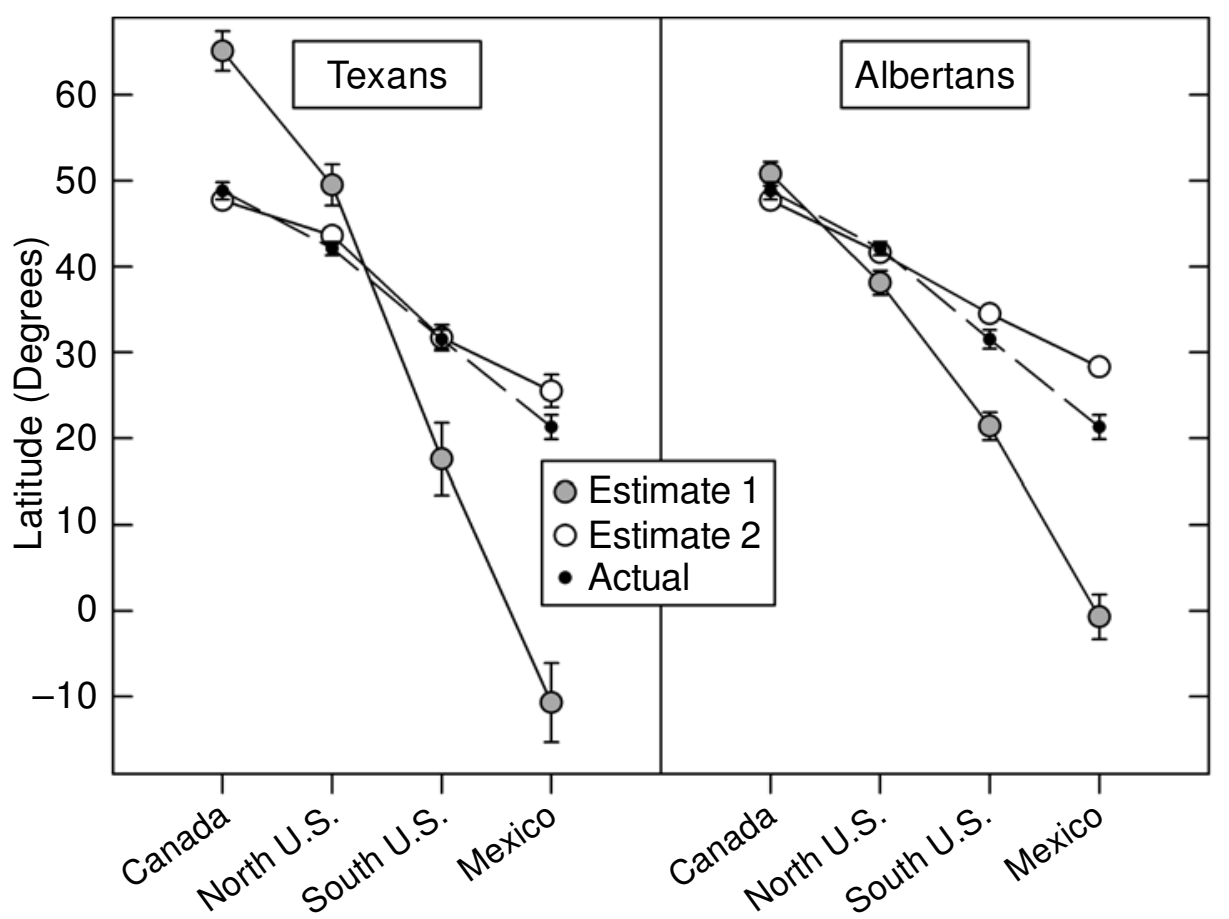

Figure 4. The average first and second estimates, and actual latitudes, for the 10 cities within each of the four subjective North American regions. Error bars are standard errors of the means within regions, computed across participants separately for each estimate; where they seem to be missing, they are too small to be seen.

\section{DISCUSSION}

Both Albertans and Texans had similar subjective representations of the gross aspects of North American geography: Both groups divided North America into the same four regions and made their most biased and least accurate estimates to the Mexican cities. Both groups also underestimated the locations of cities in the southern U.S. That the Texans did this is particularly important, because it argues against the proximity hypothesis and also undermines familiarity as an important factor in biased performance. Consistent with this conclusion are the data showing that both groups responded similarly to the information conveyed by the seed cities, regardless of their initial differences in knowledge ratings and location estimates. In addition, the underestimation of the southern U.S. by participants who live within the region provides converging evidence that the underlying cause of the bias to locate certain regions of the world far to the south of their actual locations is likely to be related to beliefs about climate.

Aspects of the data also suggested that some representational details differed between groups. For example, the range assumptions appeared to differ: Whereas the Albertans used Edmonton as the northern boundary for their estimates (possibly reflecting accurate knowledge about the actual location of Edmonton), the Texans placed all the Canadian cities at approximately the Arctic Circle (possibly also reflecting beliefs about climate). Similarly, whereas the Albertans used the equator as the rough lower bound- ary of North America, the Texans used it as the upper boundary of Mexico. Because the absolute placement of regions may be influenced by which cities are in the set being estimated (Friedman \& Brown, 2000a, 2000b), and because all of our findings held when we controlled for range, we do not want to make much of differences in the range assumptions here. Rather, we want to emphasize that both groups showed the largest bias and the least accuracy in their estimates of the Mexican cities despite large differences in their physical distance to the region, and the Texans were more biased in their Mexican estimates than in their Canadian estimates. Thus, physical proximity cannot be the primary factor underlying distortions in the subjective representation of North American geography by North American participants. However, the question of cause is still open. There are several nonmutually exclusive possibilities, some with cognitive origins, others with political, cultural, and social ones. We will briefly discuss three.

First, beliefs about climate and about the location of regions relative to global landmarks like the equator are examples of cognitivelybased beliefs that can yield location judgments with pronounced biases. For example, because there is a reasonable rank-order correlation between mean annual temperature and latitude (Friedman et al., 2002), using beliefs about climate as a proxy for locating cities on the north-south dimension is not necessarily a bad strategy. But it is an imperfect one that may be partially responsible for the observed underestimation of the loca- 
tions of cities in the southern U.S., Mexico, Mediterranean Europe, and Africa (Friedman \& Brown, 2000a, 2000b; Friedman et al., 2002).

Second, it is possible for geopoliticallybased beliefs to produce biases in geographical representations and judgments; we have already mentioned the observation that people exaggerate distances between geopolitical borders (Maki, 1981). Third, socioculturallybased beliefs may include beliefs about cultural distance, which, in turn, may affect estimates of geographic distance (Kerkman et al., 2002; Pinheiro, 1998; Saarinen, 1973; Saarinen \& MacCabe, 1995). In the present context, for example, both Albertans and Texans may have believed that Canada is more similar to the U.S. than to Mexico. This possibility predicts that the magnitude of the psychological discontinuity between Canada and the northern U.S. should be smaller than the magnitude of the discontinuity between Mexico and the southern U.S. for both groups of participants (which is corroborated by the present data). Along similar lines, performance on a variety of estimation tasks might reflect a kind of knowledge asymmetry in which there is a tendency for people in some cultures or countries but not others to view the world from a more ego- or ethnocentric perspective (Brown, Cui, \& Gordon, in press; Pinheiro, 1998; Saarinen, 2000). For example, in the North American context, the U.S. plays the dominant economic, political, and cultural role.

That these three sources of information contribute to location estimates has general implications for theories of estimation processes. For example, if it is reasonable to assume that one's home city functions as a landmark in the context of global geography, then the present data refute the prediction that the magnitude of estimation bias should always increase as a function of distance from a familiar landmark (cf. McNamara \& Diwadkar, 1997). Equally, our data suggest that the relation between uncertainty and amount of bias is perhaps more complex than that suggested by data obtained from estimation tasks in which the stimulus domain is relatively spare (e.g., estimating dot locations or locations of entities on "maps" learned in the laboratory; Huttenlocher et al., 1991; Huttenlocher et al., 2000; McNamara \& Diwadkar, 1997; Newcombe et al., 1999).

In the same way that well-selected seeds can correct geographical biases, a potentially fruitful way to reveal the source of these biases is to test participants from wellselected locations, as we have begun to do with the present study. Indeed, if we had just tested the Albertans we would conclude that the proximity hypothesis had gained support; it is notable that the strongest remaining evidence in favor of physical proximity affecting bias in a monotonic fashion comes from participants who were also located in a very northerly city (i.e., Stockholm; Lundberg \& Ekman, 1973). Being located near the "boundary" of a range may provide both a known and relatively accurate reference point.

In addition to testing participants from different locations, we may begin to tease apart the sociocultural ori- gins of geographic biases by developing instruments designed to measure beliefs about cultural similarities and differences (Kerkman et al., 2002). Thus, the fundamental idea underlying this approach is to begin to identify representational differences in world regional geography attributable to many different causes.

As noted earlier, the cognitive, geopolitical, and sociocultural sources of geographical biases are not mutually exclusive; indeed, that is part of the theoretical point. Our approach acknowledges that many factors play a role in judgment and decision-making because judgments in complex domains are based on information from different sources. Thus, both cross-cultural and cross-national studies can provide a rich source of information about the cognitive and social factors that underlie biases and misconceptions about the world.

\section{REFERENCES}

Brown, N. R., CuI, X., \& Gordon, R. (in press). Estimating national populations: Cross-cultural differences and availability effects. Applied Cognitive Psychology.

Brown, N. R., Friedman, A., \& Lee, P. J. (2002). Distance estimates reflect objective and subjective geographical categories. Unpublished manuscript.

Brown, N. R., \& Siegler, R. S. (1993). Metrics and mappings: A framework for understanding real-world quantitative estimation. Psychological Review, 100, 511-534.

Brown, N. R., \& Siegler, R. S. (1996). Long-term benefits of seeding the knowledge base. Psychonomic Bulletin \& Review, 3, 385-388.

Brown, N. R., \& Siegler, R. S. (2001). Seeds aren't anchors. Memory \& Cognition, 29, 405-412.

Collins, A., \& Michalski, R. (1989). The logic of plausible reasoning: A core theory. Cognitive Science, 13, 1-49.

Friedman, A., \& Brown, N. R. (2000a). Reasoning about geography. Journal of Experimental Psychology: General, 129, 193-219.

FrIEdman, A., \& Brown, N. R. (2000b). Updating geographical knowledge: Principles of coherence and inertia. Journal of Experimental Psychology: Learning, Memory, \& Cognition, 26, 900-914.

Friedman, A., Brown, N. R., \& McGaffey, A. P. (2002). A basis for bias in geographical judgments. Psychonomic Bulletin \& Review, 9 , 151-159.

Golledge, R. G. (1993). Geographical perspectives on spatial cognition. In T. Garling \& R. G. Golledge (Eds.), Behavior and environment: Psychological and geographical approaches (Advances in Psychology, Vol. 96, pp. 16-46). Amsterdam: North-Holland.

Hofstede, G. (1980). Culture's consequences. Beverly Hills, CA: Sage. Huttenlocher, J., Hedges, L. V., \& Duncan, S. (1991). Categories and particulars: Prototype effects in estimating spatial location. Psychological Review, 98, 352-376.

Huttenlocher, J., Hedges, L. V., \& Vevea, J. L. (2000). Why do categories affect stimulus judgment? Journal of Experimental Psychology: General, 129, 220-241.

Kerkman, D. D., Stea, D., Norris, K., \& Rice, J. L. (2002). Social attitudes predict biases in geographic knowledge. Unpublished manuscript.

Lundberg, U., \& EKman, G. (1973). Subjective geographic distance: A multidimensional comparison. Psychometrika, 38, 113-121.

MAKI, R. H. (1981). Categorization and distance effects with spatial linear orders. Journal of Experimental Psychology: Human Learning \& Memory, 7, 15-32.

McNamara, T. P., \& Diwadkar, V. A. (1997). Symmetry and asymmetry of human spatial memory. Cognitive Psychology, 34, 160-190.

Newcombe, N., Huttenlocher, J., Sandberg, E., Lie, E., \& JohnSON, S. (1999). What do misestimations and asymmetries in spatial judgment indicate about spatial representation? Journal of Experimental Psychology: Learning, Memory, \& Cognition, 25, 986-996. 
Pinheiro, J. Q. (1998). Determinants of cognitive maps of the world as expressed in sketch maps. Journal of Environmental Psychology, 18, 321-339.

SAARINEN, T. F. (1973). Student views of the world. In R. M. Downs \& D. Stea (Eds.), Image and environment: Cognitive mapping and spatial behavior (pp. 148-161). Chicago: Aldine.

SAARINEN, T. F. (2000). The Eurocentric nature of mental maps of the world. Research in Geographic Education, 1, 136-178.

SAARINEN, T. F., \& MACCABE, C. L. (1995). World patterns of geographic literacy based on sketch map quality. Professional Geographer, 47, 196-204.

Stevens, A., \& Coupe, P. (1978). Distortions in judged spatial relations. Cognitive Psychology, 10, 422-437.

ToBler, W. (1961). Map transformations of geographic space. Unpublished doctoral dissertation, University of Washington.

Tobler, W. (1970). A computer movie simulating urban growth in the Detroit region. Economic Geography Supplement, 46, 234-240.

\section{NOTES}

1. For the two signed error measures (the "raw" signed error and the percentage of the range), we arranged the means for the Neuman-Keuls tests in order of magnitude of the error, ignoring the direction of the signs. For example, the mean percentages of the range for signed errors were considered in the order $-8 \%, 9 \%, 17 \%$, and $-22 \%$ for Texans' estimates of the southern U.S., northern U.S., Canadian, and Mexican cities, respectively (see Table 1). This arrangement of the means affords the most conservative test of the difference in amount of bias between the Canadian and Mexican estimates for the Texans.

2. San Antonio is about $48 \mathrm{~km}$ (30 miles) from San Marcos.

(Manuscript received May 18, 2001; accepted for publication August 23, 2001.) 